\title{
Trackkey: a Windows program for calculation and graphical presentation of fission track data ${ }^{\text {th }}$
}

\author{
I. Dunkl ${ }^{\mathrm{a}, \mathrm{b}, *}$ \\ ${ }^{a}$ Institute of Geology, University of Tübingen, Sigwartstrasse 10, D-72076 Tübingen, Germany \\ ${ }^{\mathrm{b}}$ Laboratory for Geochemical Research, Hungarian Academy of Sciences, Budapest, Hungary
}

Received 23 December 1999; received in revised form 6 October 2000; accepted 10 October 2000

\begin{abstract}
Individual dating of detrital apatite and zircon crystals in arenitic sediments by the fission track method is a useful, promising technique for provenance analysis. The ages form clusters which are characteristic for the main source areas of siliciclastic sediments. The identification of age groups and the comparison of "age patterns" of sedimentary samples require graphical presentation of the data sets. A Visual Basic program is presented for calculating the main statistical values and plotting the single grain ages. TRACKKEY provides a complete system for data processing for the external detector method using both zeta and activation calibration systems. The plots are linked to each other and they are presented in one window for better overview. The program allows fast and easy selection and grouping of individual data. (C) 2002 Elsevier Science Ltd. All rights reserved.
\end{abstract}

Keywords: Geochronology; Single-grain dating; Provenance analysis; Arenites; Statistics; Visual Basic

\section{Introduction}

Fission track (FT) geochronology is usually applied to reveal the low temperature part of the thermal history of rocks. The apatite FT system resets at $\sim 130^{\circ} \mathrm{C}$, the annealing takes place practically in the temperature range of the "oil window"- between 60 and $120^{\circ} \mathrm{C}$. Besides thermochronology, a new branch of application has gained popularity: FT chronology used for provenance studies because it is possible to date individual detrital apatite and/or zircon crystals in arenitic rocks (McGoldrick and Gleadow, 1978; Hurford et al., 1984; Cerveny et al., 1988; Hurford and Carter, 1991; Brandon, 1992; Brandon and Vance, 1992). If no postdepositional heating affected the sediment, the single-

\footnotetext{
Code available from server at http://www.iamg.org/ CGEditor/index.htm.

*Corresponding author. Institute of Geology, University of Tübingen, Sigwartstrasse 10, D-72076 Tübingen, Germany.

E-mail address: istvan.dunkl@uni-tuebingen.de (I. Dunkl).
}

grain ages preserve the FT ages of source regions of the sediment. For dating sedimentary samples, the result is not a single number, but an age distribution carrying information about the provenance of the sediments and thus, about the tectonic and palaeogeographic situation at the time of sedimentation. The evaluation of a complex age pattern is not always obvious, as the single grain data have relatively high uncertainty-usually between 15 and $40 \%$ relative error. The uncertainty depends on the number of tracks counted in one crystal (generally between $<10$ and $\sim 300$ nuclear events), which is controlled by grain characteristics such uranium content, age and size (Fig. 1). Several models have been published for the numerical treatment and separation of the components of a mixed sample (e.g. Seward and Rhoades, 1986; Dodson et al., 1988; Galbraith and Green, 1990; Brandon, 1992; Galbraith and Laslett, 1993; Sambridge and Compston, 1994; Garver and Brandon, 1994). However, graphical presentation is indispensable for the proper evaluation of a sample and also for the visualization of the age clusters defined by the previously cited numerical procedures. 


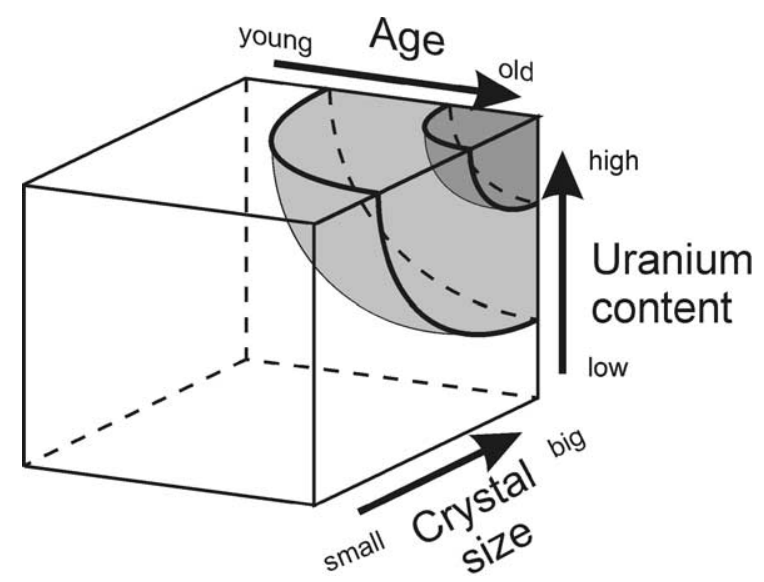

Fig. 1. Effect of properties of counted crystal on precision of fission track dating. Ideal is when crystal contains many tracks (dark gray field), but in many instances number of tracks are limited due to small size and/or young age and/or low uranium content (light gray field). These crystals are datable, but individual ages carry relatively high error. Some processed crystals may be undatable when no induced tracks are detected, or they give zero FT age due to lack of spontaneous tracks (white field).

The data groups can be marked according to different plots of the age, precision and uranium content of the individual grains.

The properties of the dated grains in sedimentary rocks carry additional important information about the source of the siliciclastic material. Thus, the registration of the shape, morphometry (in case of euhedral zircon crystals, see Pupin, 1980; Dunkl, 1992), color, type of inclusions, zoning, overgrowth, etc. is crucial and allows creation of phenotypes for an independent clustering of the single-grain age data.

Comparison of the age-distributions of different sedimentary samples and sedimentary versus crystalline samples from the proposed source areas of the sediments are the most obvious ways of interpreting single-grain age distributions. The primary measurements (namely the number of tracks) are not always suitable for direct comparison, because of the unequal parameters of the different irradiations. The raw data sets require a conversion to a common base and only single-grainage, age error, uranium content should be compared.

The aim of TRACKKEY is to provide a complete system for fission trackkers that processes measured data made by the external detector method using zeta and activation calibration systems. It calculates the main statistical parameters and tests and presents the singlegrain-data on different plots according to published algorithms. The most important plots are presented in one window for effective and fast overview. TRACKKEY allows comparison of different data sets, amalga- mation of data sets, and provides facilities to portion a data set into subsets. Its main field of usage is the evaluation of FT data measured in sedimentary rocks.

\section{Installation, start, files and dimensions}

The program is written in Visual Basic $4.0-16$ bit system; it runs under W3.x, W95-98, W2000, NT4.0 and MAC SoftWindows. Minimum system required: 486 processor, VGA graphics of $640 \times 480$ pixels. The decimal separator of Windows has to be set as dot (UK/US system). The EXE file is not able to run alone, each computer needs an installation procedure once. New versions of the program can be run without reinstallation, only the old version of the executable should be replaced by the new one. Prints can be made using black and white or color printers; the black and white prints carry all information by symbol shape.

The program asks which setting file to load at the start. The default is TK-BASE.SET. For a single user it can be the only one and it always can be updated. If the computer is used by more than one user and/or a single user has different default values e.g. using more reactors or more microscopes the various default configurations and values can be saved to different personal setting files.

\subsection{Content of files}

All data, setting and export files of the system are ASCII files, the records are always separated by commas. The users can check their content and further process the export files (see later) by any spread-sheet software able to open comma-delimited format.

The setting files contain personal default values:

- path of the working directory, where the data files are stored,

- microscopic grid size, (for the recently used microscope),

- table of zeta values for any mineral/glass combination,

- list of codes of irradiations and the $N_{\mathrm{d}}$ values,

- constants for the calculation of U content,

- preferred fission decay constant of ${ }^{238} \mathrm{U}$ (in case of activation method),

- customized setup options for the graphical display of data.

The data of the setting file(s) are used during the input of new data files; users do not need to type the previously listed default values for each sample, they appear automatically.

In the fission track dating routine the samples are always irradiated with age standards. In this way the 
average of the continuously increasing number of zeta measurements become progressively more precise and may change slightly. There are two possibilities for the age calculation of a sample: (a) to use the zeta at the time of the measurement - this zeta is stored in the data file; (b) to use the actual, latest zeta - this value is in the setting file. In this situation the ages will be recalculated automatically without the modification of the data file. This option can also be specified in the setting file.

The data files contain counting results:

- number of grains, $N_{\mathrm{s}}, N_{\mathrm{i}}$ and the measured area of the grains,

- zeta, zeta error (used at the time of counting)

- neutron fluence (in case of activation method)

- code of irradiation, RhoD,

- microscopic grid size (used during counting),

- type of the mineral and monitor glass.

The user can place comments in four text fields about the locality, sample code, stratigraphic age, petrography, but these records are optional, they may contain any type of information e.g. project name, geographical coordinates, observer. The default extension of the data files are: .APA, .ZIR, .TIT and .MIN for apatite, zircon, sphene and for other types of minerals, respectively. It is possible to relate different icons to the different mineral files. The start directory contains an icon set for this purpose: I-APA.ICO, I-ZIR.ICO and I-TIT.ICO.

The age standard files have the same format as the other data files. The zeta can be determined in the Calculations/Zeta/ menu item.

\subsection{Dimensions used}

All track densities are in $10^{5} \mathrm{track} / \mathrm{cm}^{2}$, neutron fluence is in $10^{15} \mathrm{n} / \mathrm{cm}^{2}$ and the microscope grid area in square micrometer. The ages on the main window are in $\mathrm{Ma}$; single error is presented.

\section{Main window}

After starting and opening a data file the main window shows the statistical results and the main plots (Fig. 2). Where the mouse pointer becomes a cross, a click on right mouse button shows the option window of the given plot or the "Data Edit" window when the user clicks on the statistical results.

The frame of statistical results show the main measured and calculated values such as number of crystals, area and tracks counted, track densities,

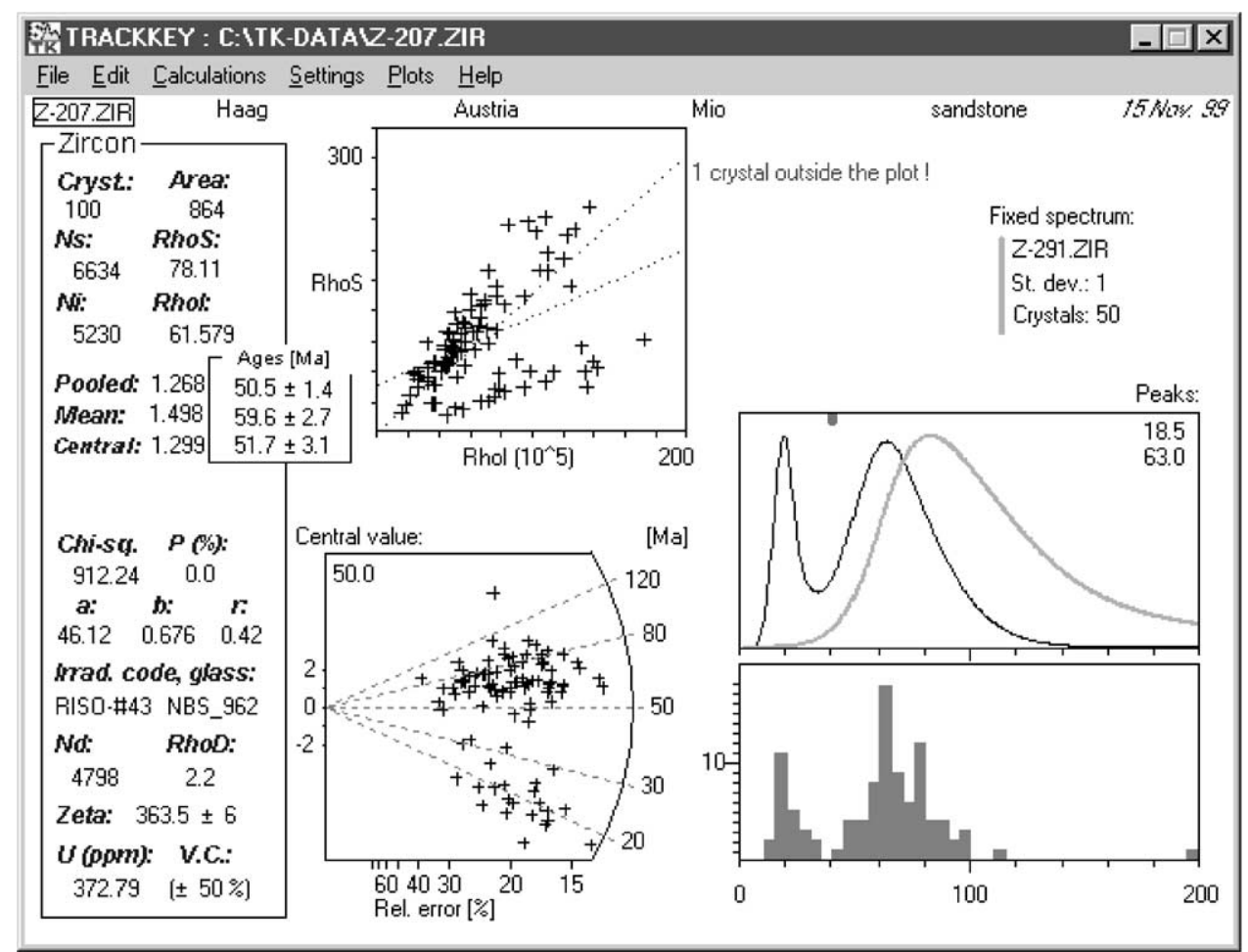

Fig. 2. Main window of TRACKKEY. Area at top right is reserved for warning messages, comments for second file loaded or for plot of length distribution. 
calculated ages, the result of the chi-square test, parameters of the linear regression, irradiation constants, zeta, the uranium content of the dated mineral and the variation coefficient of the $\mathrm{U}$ content. The calculations are based on methods described by Fleischer et al. (1964, 1965); Wagner and Reimer (1972); Hurford and Green (1983); Green (1981); Galbraith (1988, 1990) and Galbraith and Laslett (1993). For the original sources of recommended ages of the age standards see compilation of Hurford (1998). The raw data can be modified in the "Edit Data" window (Fig. 3).

$X Y$-plot shows the spontaneous/induced track density ratios, the $N_{\mathrm{s}} / N_{\mathrm{i}}$ ratios and measured area vs. $N_{\mathrm{s}} / N_{\mathrm{i}}$ ratios. Burchart (1981) and Green (1981) used such (isochron-plot-like) presentation of data. This plot shows the raw data, the age of the crystals expressed by the tangent of the lines between the origin and the data point. The RhoI is proportional to the uranium content of the individual crystals, thus, the distribution along the horizontal axis on the RhoS/RhoI plot shows the $\mathrm{U}$ distribution. For crystalline samples the Ucontent has some petrogenetic meaning (Král' and Burchart, 1983) and in case of sedimentary samples, the $\mathrm{U}$ distribution can be an additional tool for the clustering of the grains. The maximum values of the scales can be set by mouse click and retyping (I-shape of the mouse pointer locates the area). If the re-scaling causes grains to fall outside the plot area a warning message in red appears. A left mouse click on the data points shows the raw data of the depicted single crystal. A right mouse click shows the options for this plot, allowing the user to reject grains.

The age-spectrum (probability density diagram, see Fig. 2) is calculated according to Hurford et al. (1984). A left mouse click marks a given age both on the agespectrum plot and on the radial plot; the cumulative percentage at that marked age is also shown. In this way the lag time (Garver and Brandon, 1994) of the age groups can be visualized easily. Two of such age markers can be present in the same time. The difference of the cumulative values between two time markers gives a percentage of the age distribution of the given time interval. Such probabilities of the main age clusters can be used to characterize the age-pattern of the catchment area of a (paleo) river. This kind of analysis is a careful step towards the more quantitative evaluation of singlegrain FT data from sediments. It is also biased by many random factors (mainly by the low number of grains and unequal quality), but it is more realistic than to consider only the number of grains in time intervals. The option window of the age-spectrum plot (available via right mouse click on the plot) contains graphical options to customize the graphs and allows to fix the actual agespectrum as a background plot for comparisons with other data sets (Fig. 4). When opening other data files,

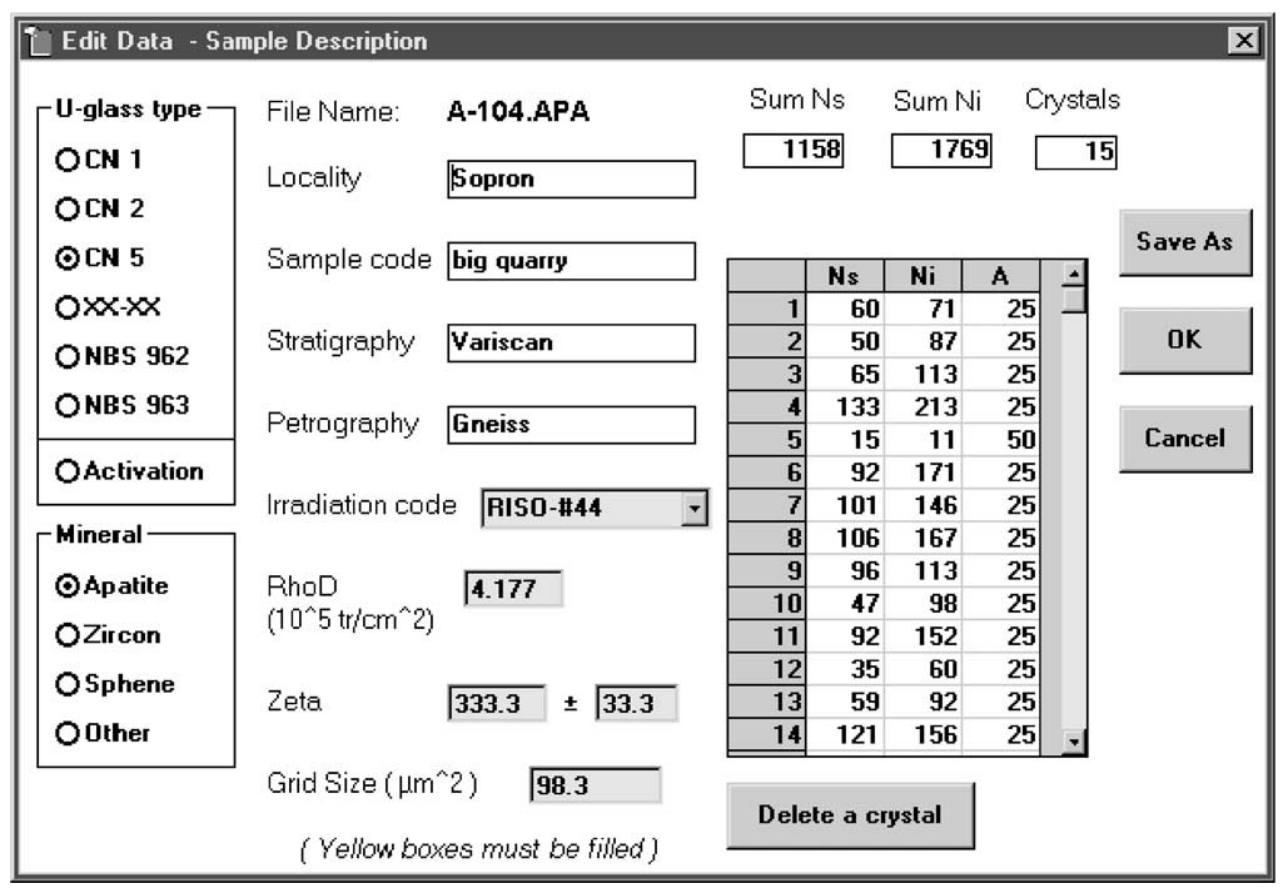

Fig. 3. Window for processing of data files. 


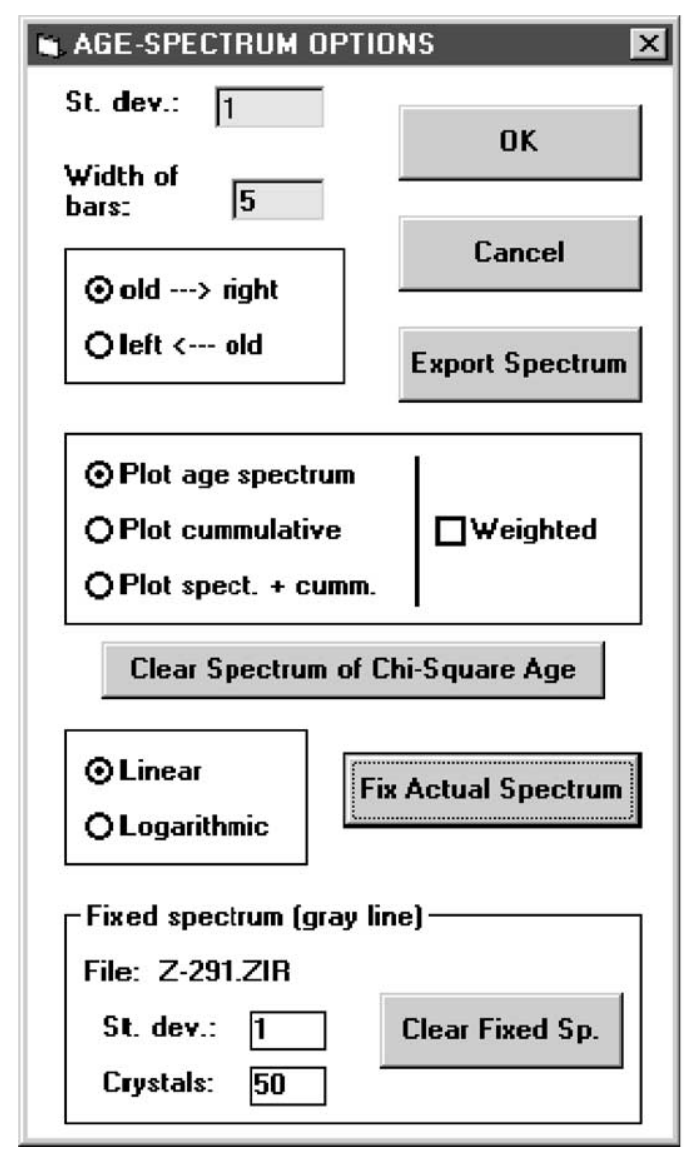

Fig. 4. Options of age-spectrum plot.

this fixed wall-paper-like background plot will remain (see gray line in age spectrum of Fig. 2) but, can also be switched off.

The age-spectrum method was explained in detail by Brandon (1996) and it was criticised by Galbraith (1998), but since it is a useful visualization that already was introduced and accepted by users the main window contains this plot. One of the problematic points with this kind of presentation is that the different $N_{\mathrm{s}}$ and $N_{\mathrm{i}}$ numbers of the young and old crystals result in different standard deviations at the younger and older part of the range of ages. This has an effect on the shape of agespectrum. If the age of a crystal is close to the "one-toone-age" of the irradiation (when $N_{\mathrm{s}} / N_{\mathrm{i}}=1$ ) the bias is minor. However, when a cluster of old ages lies far from the one-to-one-age of the irradiation, the older part of the age-spectrum tends to be flat. This is why TRACKKEY shows the one-to-one age of the actual irradiation (by a small brown bar at the top) and this mark can help to judge how proportional this kind of bias is along the range of ages. If the one-to-one age of the irradiation is $\frac{1}{3}-\frac{1}{4}$ as old as the oldest age cluster, then the appearance of the oldest group can be misleadingly flat on the age-spectrum.

The radial plot is calculated following Galbraith (1988, 1990). Fig. 5 shows the possibilities of the graphical layout.

\section{File operations}

\subsection{Import-export}

TRACKKEY can import data files of some fission track laboratories and the grain-age files created from the data files. The data can be exported in the format of Mark Brandon's BINOMFIT programs (extension: .FTZ; see Brandon, 1992; Garver and Brandon, 1994) - see File/Export/Yale format data file/ menu item. These files can be used for Brandon's peak-fitting algorithm. Another export possibility is the grain-age file (extension: .AGE). It contains the calculated values for the grains and makes it possible to compare data sets produced under different irradiation conditions. From these files, the single grain-ages can be extracted to make input files for other programs, e.g. for AFTSOLVE (Ketcham et al., 2000). The age-spectrum files (extension: .SPE) save the age probability density plot according to the latest formatting step. The scale is subdivided for 400 intervals, allowing high-quality graphics for publications to be made with any spreadsheet program. These files record the "absolute", the "corrected" and the "cumulative" age-spectra. In the case of "absolute" calculation, the area below the curve is identical with the number of grains with age $>0 \mathrm{Ma}$. Using this column for comparison of different files the age spectrum lines will be proportional to the dated grains of the samples. The maximum of the "corrected" age-spectrum is normalized to 100 . Using these records different files will give spectra with uniform heights. The Help/File Formats/ menu item shows the structure of this kind of export files.

The menu item Export/DXF file (vector graphics) creates files in AutoCAD compatible format, which contain the three graphics of the Main Window. These files can be imported and edited by drawing programs (e.g. AutoCAD, CorelDraw, Micrografx, Canvas, Surfer, Adobe Illustrator, ArcView, ERMapper).

\subsection{Comparison and addition of files}

In the analysis of sedimentary samples, the graphical comparison of the samples is an important aspect of the evaluation. If different crystal mounts have been irradiated in the same package, the experimenter can simply compare the data files (Fig. 6) with the File/ Compare Files/Load another Data file/ menu item. Such files can be amalgamated and saved. It can provide help 


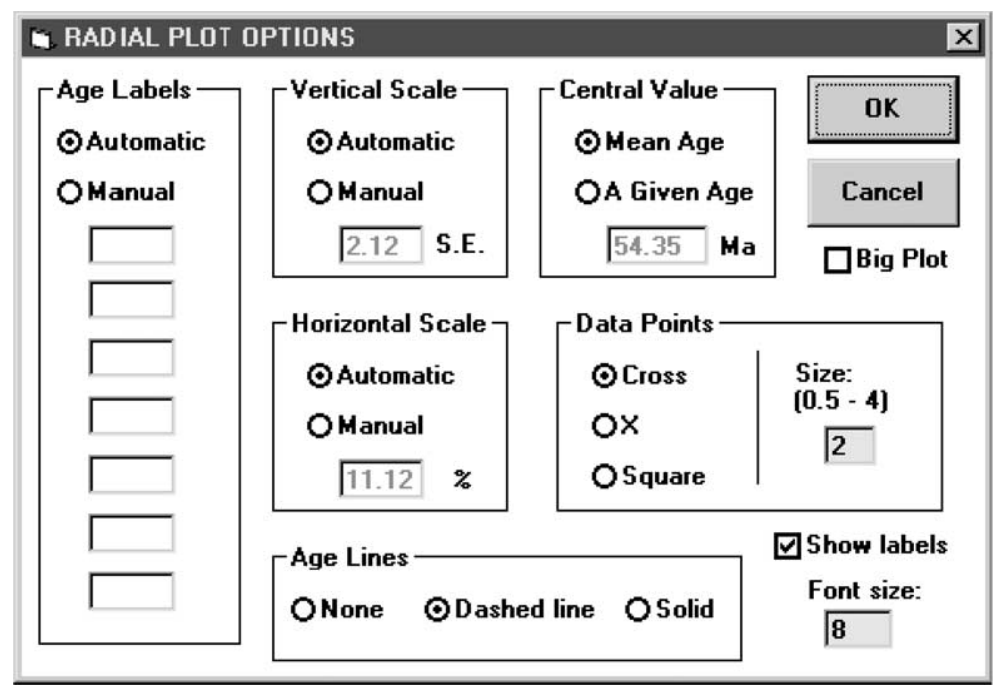

Fig. 5. Options of radial plot.
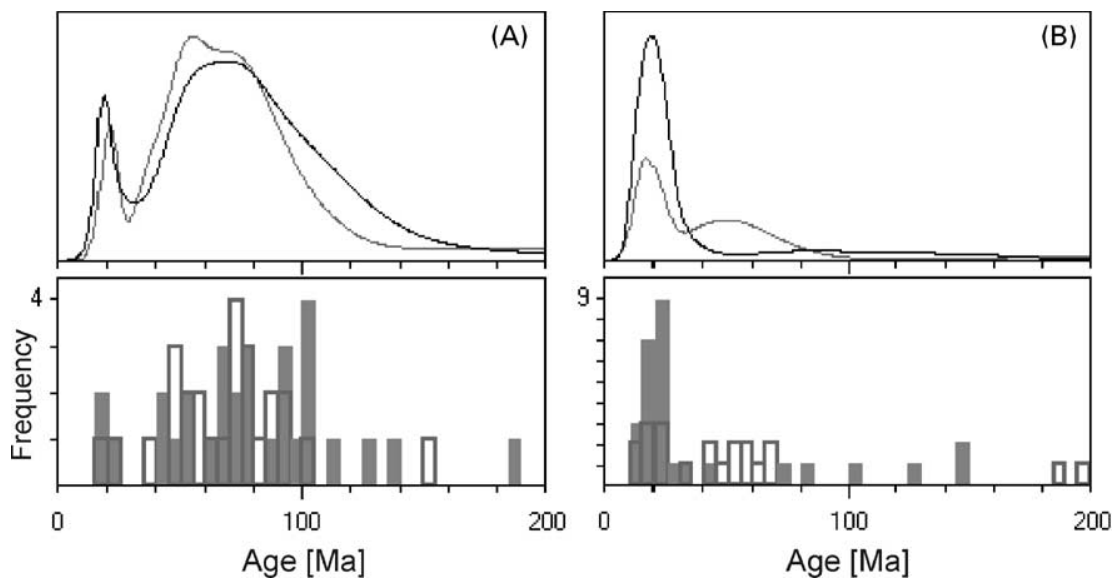

Fig. 6. Part of main window, showing age spectra and column diagrams of samples composed of two differently etched mounts. (A) Two age distributions are rather similar, both mounts contain principal age clusters in similar proportions. (B) Mounts yield different age clusters. Group of ages around $60 \mathrm{Ma}$ is completely missing from short-etched sample. Interpretation needs care; additional counting (and maybe etching) is necessary.

in the evaluation of two or more differently etched zircon mounts produced from the same sample (see e.g. Naeser et al., 1987). If the irradiations of the samples were performed in different conditions the comparison of the raw data is not possible. In this case the results have to be exported first as grain-age files (File/Export/ menu item) and the grain-age files are suitable for comparison. It is possible to create a composite file, which will automatically record the file names and the number of grains of the added files (detailed explanation in Help/File Formats/ menu items). The frame of the statistical results and the $X-Y$ plot are not presented when an age file is loaded, because the values are not comparable in different files.

\subsection{Summarizing table from more files}

The File/Table from More Files/ menu item creates a compilation table from selected data files. Before this action the user must produce a simple text file that contains the list of data files to be combined. The resulting file will contain all the data, roughly in the sequence of the recommendation of I.U.G.S. (Hurford, 
1990). The user can delete the unnecessary columns when a report is compiled from the table file.

\section{Other important menu items}

\subsection{Chi-square Age}

The youngest age group in a sample usually has a specific meaning in the evaluation of the source area. It can be volcanogenic or may indicate the exhumation of a rapidly cooled metamorphic core complex. That is why the test of the "youngest part" of the single-grain age distribution is important. Brandon (1992) and Brandon Vance (1992) proposed decomposing of the grain ages into populations according to the chi-square test of the sub populations. Fig. 7 shows the "Chi-square Age" window, where the crystals are ordered according to increasing age and the $\operatorname{Sum} N_{\mathrm{s}}$, Sum $N_{\mathrm{i}}$, probability and age of the cumulating sub-populations are presented. The user can mark the first $n$ grains to be plotted on the age-spectrum and also can reject them to see and test the older age-cluster. This method is especially useful when a sandstone contains a syn-sedimentary volcanic contribution. By filtering out this population, the older, erosion-related detrital apatite or zircon crystals will be clearly observable.

\subsection{Accumulation Plot}

There are several algorithms published on the calculation of the error of the FT age (see e.g. Johnson et al., 1979; Green, 1981). Most authors agree that the error is mainly controlled by the number of tracks counted when the sample passes the chi-square test. In case of external detector method and using a zeta calibration, the following equation is used to express the error:

$\sigma(T)=T \sqrt{\frac{1}{N_{\mathrm{s}}}+\frac{1}{N_{\mathrm{i}}}+\frac{1}{N_{\mathrm{d}}}+\left[\frac{\sigma(\zeta)}{\zeta}\right]} 2$

where $T=$ age; $N_{\mathrm{s}}, N_{\mathrm{i}}$ and $N_{\mathrm{d}}=$ Numbers of spontaneous, induced and dosimeter tracks; $\zeta$ and $\sigma(\zeta)=$ zeta and error of zeta determined using age standards.

However, Green (1981) recalled the dangers of the mechanical application of this equation. He pointed out that the bias due to uncontrollable geometric problems during the microscopic observation (due to mainly the heterogeneous distribution of uranium) can be reduced only by the increasing of the number of grains. A

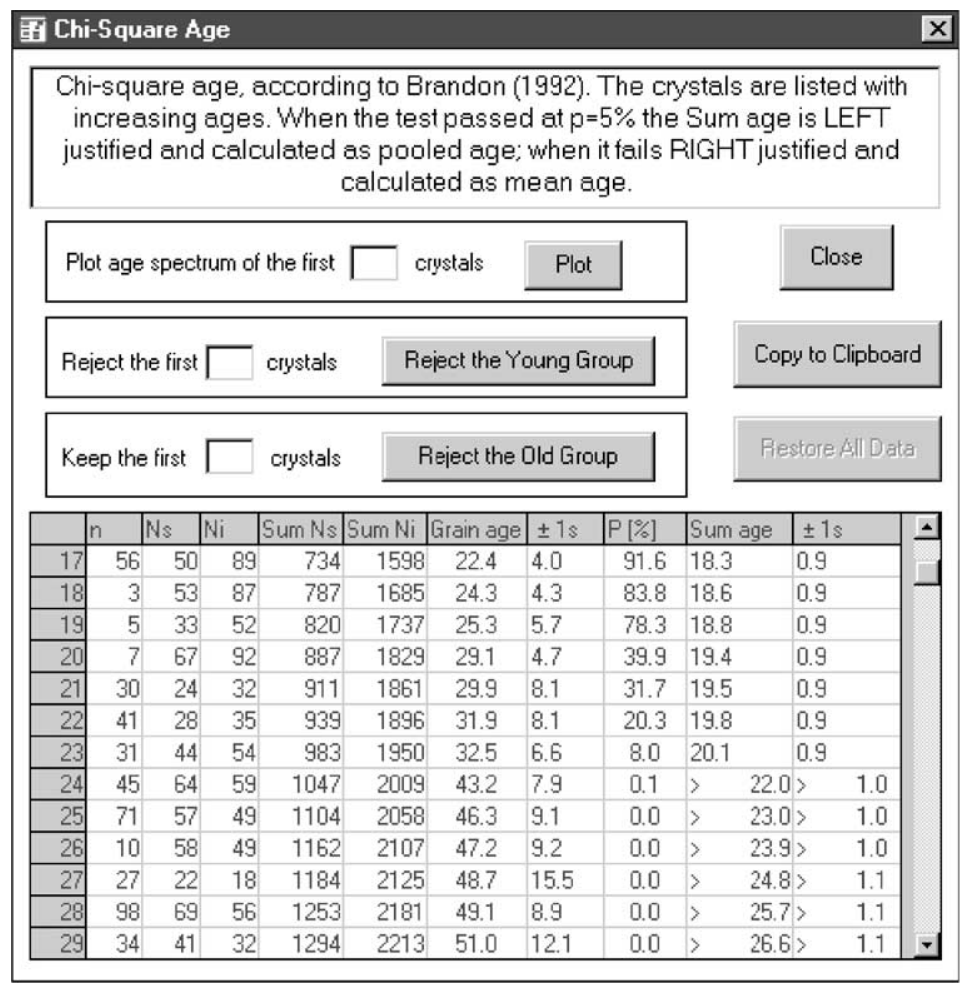

Fig. 7. Window of chi-square age calculation. First 23 crystals form young, "chi-square age" population, gap in single grain ages and drop in chi-square value indicate that this subdivision is reliable. 
minimum of 25 grains were suggested to be counted to achieve a high-precision analysis. The intra-grain heterogeneity causes extra-Poissonal error, but the inter-grain heterogeneity carries another danger. If the sample contains apatite grains of very low and very high $\mathrm{U}$ content, it is typical that only a few grains carries the majority of the counted tracks. They may strongly bias the age, however the whole sample has acceptable track numbers and acceptable-looking bulk statistical results. This problem occurs also when the $\mathrm{U}$ content is not very scattered, but the average counts are low and a part of the dated grains contain zero spontaneous tracks. The grain accumulation plot (Fig. 8) presents the mean ages calculated from the first $1,2,3, \ldots, n$ grains. Such a plot (Seward and Kohn, 1997 named it a running means plot) could show clearly the bias caused by individual grains and helps to judge the crucial question: is the number of dated grains enough? (see Copeland and Peters, 1997). A considerable shift at the end of the plot indicates the necessity of the continuation of track counting. If the enlargement of the data set is not possible, an unbalanced grain accumulation plot (see Fig. 8) warns the user that the real uncertainty of the FT age may exceed the numerically calculated error and such a result needs careful interpretation.

\subsection{Help}

The help items contain the most essential information about the methods and options of the software. The format and content of data and export files are presented with some explanation. The equations and constants used for the calculations as well as their references are also listed.

\section{Conclusions and recommendations}

Sneyd (1984), Tagami et al. (1988), Mark Brandon and Rod Brown already published or distributed programs for managing FT data. James Talbot's program for Macintosh draws radial plots. The main advantages of TRACKKEY over the former ones are the more flexible import-export facilities, the easy grouping of the single-grain data, the presentation of more types of graphics, and the link of the plots in one window. It calculates the latest published statistical parameters, such as central age (Galbraith and Laslett, 1993). It is recommended for provenance studies and to reveal the meaning of age distributions of complex samples (partly reset hard rock and sediment samples).

\subsection{Software availability}

The program as described in this paper, a short READ.ME for the installation and several example files are available on the iamg server. Later versions will be placed on the web site of University of Tübingen. On request the author can write additional import filters to

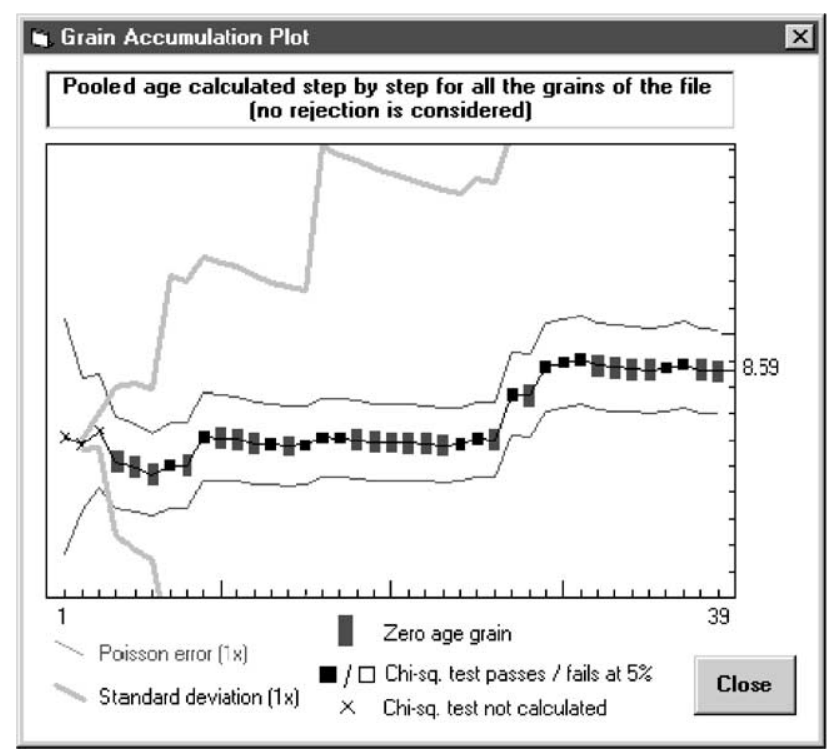

Fig. 8. Grain-accumulation plot presents running mean, Poisson error of first $n$ crystals and standard deviation of individual grain data. This sample contains significant number of zero-track grains and some grains of high track number. These grains are strongly biasing bulk age. Thus, 39 crystals are insufficient to give reliable age. Note that "Poisson" error is much smaller than standard deviation of grain ages and how misleading "passes" of chi-square test can be. 
read other types of data files. The program is freeware, but the author kindly asks the users to cite this paper.

\section{Acknowledgements}

The author thanks his family and his students for their patience. The program was tested and the manuscript was improved by B. Székely and F. Moser (Tübingen) and A. Carter (London), thanks for their valuable aid. The author thanks J. Talbot and M. Brandon for sending their programs. This work is a contribution to the projects supported by the Hungarian National Scientific Research Fund (OTKA Project No. 232/91) and the German Science Foundation in the frame of the Collaborative Research Centre 275. Constructive reviews by two anonymous reviewers and M.T. Brandon were much appreciated and improved both content and style.

\section{References}

Brandon, M.T., 1992. Decomposition of fission-track grain-age distributions. American Journal of Science 292, 535-564.

Brandon, M.T., 1996. Probability density plot for fission-track grain-age samples. Nuclear Tracks and Radiation Measurements 26 (5), 663-676.

Brandon, M.T., Vance, J.A., 1992. Tectonic evolution of the cenozoic Olympic subduction complex, Washington state, as deduced from fission track ages for detrital zircons. American Journal of Science 292, 565-636.

Burchart, J., 1981. Evaluation of uncertainties in fission-track dating: some statistical and geochemical problems. Nuclear Tracks and Radiation Measurements 5 (1/2), 87-92.

Cerveny, P.F., Naeser, N.D., Zeitler, P.K., Naeser, C.W., Johnson, N.M., 1988. History of uplift and relief of the Himalaya during the past 18 million years-evidence from fission-track ages of detrital zircons from sandstones of the Siwalik group. In: Kleinspehn, K.L., Paola, C. (Eds.), New Perspectives in Basin Analysis. Springer, Berlin, pp. 43-61.

Copeland, P., Peters, C., 1997. Dating detrital minerals: how many is enough? Geological Society of America Annual Meeting, Abstract with Programs, Salt Lake City, p. 420.

Dodson, M.H., Compston, W., Williams, I.S., Wilson, J.F., 1988. A search for ancient detrital zircons in Zimbabwean sediments. Journal of the Geological Society of London 145 (6), 977-983.

Dunkl, I., 1992. Origin of eocene-covered karst bauxites of the Transdanubian Central Range (Hungary): evidence for early eocene volcanism. European Journal of Mineralogy 4, 581-595.

Fleischer, R.L., Price, P.B., Walker, R.M., 1964. Fission-track ages of zircons. Journal of Geophysical Research 69 (22), 4885-4888.

Fleischer, R.L., Price, P.B., Walker, R.M., 1965. Tracks of charged particles in solids. Science 149, 383-393.

Galbraith, R.F., 1988. Graphical display of estimates having differing standard errors. Technometrics 30, 271-281.
Galbraith, R.F., 1990. The radial plot; graphical assessment of spread in ages. Nuclear Tracks and Radiation Measurements 17 (3), 207-214.

Galbraith, R.F., 1998. The trouble with probability density plots of fission track ages. Nuclear Tracks and Radiation Measurements 29 (2), 125-131.

Galbraith, R.F., Green, P.F., 1990. Estimating the component ages in a finite mixture. Nuclear Tracks and Radiation Measurements 17 (3), 197-206.

Galbraith, R.F., Laslett, G.M., 1993. Statistical models for mixed fission track ages. Nuclear Tracks and Radiation Measurements 21 (4), 459-470.

Garver, J.I., Brandon, M.T., 1994. Erosional denudation of the British Columbia Coast Ranges as determined from fissiontrack ages of detrital zircon from Tofino basin, Olympic peninsula, Washington. Bulletin of Geological Society of America 106, 1398-1412.

Green, P.F., 1981. A new look at statistics in fission track dating. Nuclear Tracks and Radiation Measurements $5(1 / 2), 77-86$.

Hurford, A.J., 1990. Standardization of fission track dating calibration: recommendations by the Fission Track Working Group of the IUGS. Subcommission on Geochronology. Chemical Geology 80, 171-178.

Hurford, A.J., 1998. Zeta: the ultimate solution to fission-track analysis calibration or just an interim measure? In: Van den haute, P., De Corte, F. (Eds.), Advances in Fission-Track Geochronology. Kluwer Academic Publishers, Dordrecht, The Netherlands, pp. 19-32.

Hurford, A.J., Carter, A., 1991. The role of fission track dating in discrimination of provenance. In: Morton, A.C., Todd, S.P., Haughton, P.D.W. (Eds.), Developments in Sedimentary Provenance Studies. Geological Society Special Publication, Geological Society of London, pp. 67-78.

Hurford, A.J., Fitch, F.J., Clarke, A., 1984. Resolution of the age structure of the detrital zircon populations of two Lower Cretaceous sandstones from the Weald of England by fission track dating. Geological Magazine 121, 269-277.

Hurford, A.J., Green, P.F., 1983. The zeta age calibration of fission-track dating. Chemical Geology 41, 285-312.

Johnson, N.M., McGee, V.E., Naeser, C.W., 1979. A practical method of estimating standard error of age in the fission track dating method. Nuclear Tracks 3, 93-99.

Ketcham, R.A., Donelick, R.A., Donelick, M.B., 2000. AFTSolve: a program for multi-kinetic modeling of apatite fission-track data. Geological Material Research. 2 (1), 1-32.

Král', J., Burchart, J., 1983. Dispersion of uranium in accessory apatite in crystalline rocks and its possible petrogenetic meaning. Earth and Planetary Science Letters 63, 34- 40 .

McGoldrick, P.J., Gleadow, A.J.W., 1978. Fission-track dating of Lower Palaeozoic sandstones at Tatong, north central Victoria. Journal of the Geological Society of Australia 24 (7-8), 461-464.

Naeser, N.D., Zeitler, P.K., Naeser, C.W., Cerveny, P.F., 1987. Provenance studies by fission-track dating of zircon-etching and counting procedures. Nuclear Tracks and Radiation Measurements 13, 121-126.

Pupin, J.P., 1980. Zircon and granite petrology. Contributions to Mineralogy and Petrology 73, 207-220. 
Sambridge, M.S., Compston, W., 1994. Mixture modeling of multi-component data sets with application to ion-probe zircon ages. Earth and Planetary Science Letters 128, 373-390.

Seward, D., Kohn, B.P., 1997. New zircon fission-track ages from New Zealand Quaternary tephra: an interlaboratory experiment and recommendations for the determination of young ages. Chemical Geology 141, 127-140.

Seward, D., Rhoades, D.A., 1986. A clustering technique for fission track dating of fully to partly annealed minerals and other non-unique populations. Nuclear Tracks and Radiation Measurements 11 (4/5), 259-268.
Sneyd, A.D., 1984. A computer program for calculating exact confidence intervals for age in fission-track dating. Computers \& Geosciences 10 (2-3), 339-345.

Tagami, T., Lal, N., Sorkhabi, R.B., Ito, H., Nishimura, S., 1988. Fission track dating using external detector method: a laboratory procedure. Memoirs of the Faculty of Science, Kyoto University, Series of Geology and Mineralogy, vol. LIII, pp. 1-30.

Wagner, G., Reimer, G.M., 1972. Fission-track tectonics: the tectonic interpretation of fission track apatite ages. Earth and Planetary Science Letters 14, 263-268. 